\title{
Construção Coletiva de Experiências Inovadoras no Processo Ensino-aprendizagem na Formação de Profissionais da Saúde*
}

\author{
Collective Construction of Innovative Experiences in \\ the Teaching-learning Process of Health Professionals
}

Maria de Lourdes da Silva Marques Ferreira ${ }^{I}$ Rosângela Minardi Mitre Cotta ${ }^{I I}$

Marilda Siriani de Oliveira ${ }^{I I I}$

\author{
PALAVRAS-CHAVE \\ - Construção coletiva. \\ - Aprendizagem. \\ - Metodologia. \\ - Sujeito coletivo. \\ - Cuidados de saúde. \\ - Pessoal e saúde.
}

$\frac{\text { REVISTA BRASILEIRA DE EDUCAÇ̃̃o MÉDICA }}{33(2) \cdot 240-246 \cdot 2009}$
Recebido em: 06/06/2007

Aprovado em: 24/09/2008

\section{KEYWORDS}

- Collective construction.

- Learning.

- Methodology.

- Collective subject.

- Delivery of health care.

- Health personel.

$24033(2): 240-246 ; 2009$
"Trabalho realizado durante o Curso de Especialização e Formação de Tutores Semipresencial - Ativação de Processos de Mudança na Formação Superior de Profissionais de Saúde, promovido pelo Ministério da Saúde do Brasil, Fiocruz e Rede Unida.

${ }^{\text {I }}$ Faculdade de Medicina de Botucatu, São Paulo, Brasil.

"Iniversidade Federal de Viçosa, Minas Gerais, Brasil.

${ }^{\text {III }}$ Faculdade de Medicina de Marília, São Paulo, Brasil. 


\section{INTRODUÇÃO}

Refletir sobre as práticas de Saúde implica refletir sobre a formação e o desenvolvimento dos profissionais da área, através dos modos de ensinar e aprender nas academias e das formas de educar, cuidar, tratar e acompanhar as pessoas que necessitem de assistência à saúde.

O desafio da mudança da prática encontra-se no pressuposto de que o professor se libere do modelo tradicional de ensino, empenhando-se em construir uma nova prática, adotando o papel de educador ${ }^{1}$.

Buscar e analisar as transformações da prática significa rever as relações de poder existentes nas instituições de Saúde entre profissionais, usuários e gestores².

Essas transformações potencializam a construção de vínculo, aproximando quem oferece ou presta serviço de quem o recebe, e personalizando a relação, que deve ser compromissada, solidária e aparecer como fruto de uma construção social e parte de um esforço que envolve equipe, instituições e comunidade ${ }^{3}$.

Transformar a formação e a gestão do trabalho em Saúde não deve ser uma questão simplesmente técnica, pois envolve mudanças: nas relações, nos processos, nos atos de Saúde e, principalmente, nas pessoas. No campo da Saúde, o papel de constatar a realidade e de produzir sentidos pertence tanto ao SUS como às universidades e demais instituições formadoras. Cabe ao SUS e às universidades coletar, sistematizar, analisar e interpretar permanentemente informações da realidade, problematizar o trabalho e as organizações de Saúde e de ensino, e construir significados e práticas com orientação social, mediante a participação ativa dos gestores setoriais, formadores, usuários e estudantes ${ }^{4}$.

Tratando-se de um curso à distância, a internet assume via essencial das trocas, intercâmbio, inter-relações e construção do conhecimento. Tem-se assinalado como uma das principais características da internet o fato de ela ser um instrumento de facilitação da emergência de um pensamento coletivo, que vem acompanhada da correlata sensação de se pertencer à famosa "aldeia global"5.

Os fóruns nos cursos à distância permitem aos participantes um debate em busca de uma construção coletiva, sobre uma temática específica, por meio da questão norteadora que possibilita que o conteúdo das mensagens discuta as indagações refletidas pelo grupo.

Desta perspectiva, este trabalho tem como objetivo central analisar a produção coletiva, sobre o eixo temático de: o quê, o como e por que mudar para provocar e produzir a mudança almejada na formação dos profissionais de Saúde, no fórum intitulado Quando a pergunta qualifica o olhar, do curso de espe- cialização semipresencial em Ativação de processos de mudança na formação superior de profissionais de Saúde, promovido pelo Ministério da Saúde, Fiocruz e Rede Unida.

\section{SUJEITOS E MÉTODOS}

O corpus analisado é constituído por 132 participações e formado por dez profissionais de Saúde vinculados a academias e serviços de Saúde, coordenados por um orientador de aprendizagem que atuou como facilitador.

Desde o marco teórico da metodologia ativa, o orientador de aprendizagem tem o propósito de promover o autodescobrimento (insight - o dar-se conta). As intervenções do orientador de aprendizagem tentam gerar reflexões dos participantes, assim como a formulação de perguntas que deixem em descoberto certos aspectos da problemática. O esforço é centrado em lograr que os próprios integrantes do grupo, por meio da visualização dos "conflitos", possam interatuar de forma adequada e se instrumentalizem para pôr em prática as necessárias transformações em suas "aldeias", como parte de suas reflexões, críticas e mudanças ${ }^{6,7}$.

$\mathrm{O}$ trabalho se desenvolveu no fórum intitulado Processamento da situação da prática, denominada Quando a pergunta qualifica o olhar, por meio da discussão das seguintes questões: Como se deu historicamente a construção do conceito de cuidado a partir dos diferentes saberes-profissões?; Como lidar com uma experiência focal (inovadora) de ensino-aprendizagem? E Como garantir a governabilidade-viabilidade inovadoras a experiências como estas no contexto da gestão?

A história das diferentes profissões no que se refere ao cuidado nos leva a um processo de reflexão sobre a necessidade de construir novos saberes, contemplando o quê, como e por que mudar. A partir da percepção da necessidade de mudança, refletir sobre as mudanças pontuais e as estratégias administrativas para garantir as experiências inovadoras. Isto implica mudar do ensino tradicional para o ensino inovador com repercussão na prática profissional, garantindo à comunidade uma assistência e atividades de educação permeadas pelo diálogo, e não de maneira autoritária.

O mundo em que vivemos se transforma, nos transforma e é transformado por nós, daí a idéia de que o ser humano é um eterno aprendiz.

No curso Ativação de processos de mudança na formação superior de profissionais de Saúde, o fórum é uma das metodologias utilizadas à distância. Ocorre sempre após uma oficina presencial em que os assuntos pertinentes são discutidos em grupo, após a busca ativa de materiais e conteúdos por parte dos membros do grupo. Ao final, elabora-se, a pergunta (questão de aprendizagem) a ser trabalhada no fórum, on-line. 
As mensagens aqui analisadas correspondem à produção coletiva do grupo durante o período de 20-06-2005 a 13-08-2005.

\section{Análise das mensagens}

Buscou-se analisar as mensagens utilizando os instrumentos de análise qualitativa de discursos por meio das figuras metodológicas ${ }^{8}$. Neste estudo, os instrumentos de análise são: a idéia central e o discurso do sujeito coletivo.

O discurso do sujeito coletivo (DSC) é uma estratégia metodológica que visa tornar mais clara uma dada representação social. Consiste na reunião, num só discurso, de vários discursos individuais emitidos como resposta a uma mesma questão de pesquisa, por sujeitos sociais e institucionalmente equivalentes ou que fazem parte de uma mesma cultura organizacional e de um grupo social homogêneo, na medida em que tais indivíduos ocupam a mesma posição ou posições vizinhas num dado campo social. Os pensamentos e falas dos sujeitos são obtidos mediante entrevistas baseadas em roteiros semi-estruturados ${ }^{9}$.

Para a análise dos depoimentos, foi utilizado no discurso do sujeito coletivo o recurso de três figuras metodológicas"

- Expressões-chave (EC) - transcrições literais de parte dos depoimentos, contínuos ou não, que permitem resgatar a sua essência;

- Idéia central (IC) - afirmações que permitem traduzir o essencial do discurso. É a síntese do discurso;

- Discurso do sujeito coletivo (DSC) - busca-se somar discursos, reconstruir, a partir de trechos dos discursos individuais, tantos discursos homogêneos quantos se julgue necessários para expressar o pensamento daquele universo estudado sobre um fenômeno.

Para efeito de análise dos depoimentos, a idéia central é entendida como a síntese do conteúdo discursivo explicitado pelos sujeitos. São as afirmações, negações e dúvidas a respeito da realidade factual, bem como os juízos de valor a respeito da realidade institucional e do contexto onde os sujeitos estão envolvidos ${ }^{8}$.

O DSC é uma forma de expressar diretamente a representação social de um sujeito social ${ }^{9,10}$.

A técnica de pesquisa qualitativa é um procedimento de tabulação de depoimentos verbais. Por meio da análise de entrevistas, de relatos escritos e a partir de um roteiro de questões abertas, extraem-se de cada uma das respostas as idéias centrais e suas correspondentes expressões-chave. Então, são compostos um ou vários DSCs - discursos-síntese enunciados na primeira pessoa do singular, como se fossem a fala ou o depoimento de uma coletividade ${ }^{11}$.

Os passos seguidos até a síntese dos discursos foram: (a) leitura do conjunto dos depoimentos coletados nas entre- vistas; (b) leitura da resposta a cada pergunta em particular, marcando as expressões-chave selecionadas; (c) identificação das idéias centrais de cada resposta; (d) análise de todas as expressões-chave e idéias centrais, agrupando as semelhantes em conjuntos homogêneos; (e) identificação e nomeação da idéia central do conjunto homogêneo, que será uma síntese das idéias centrais de cada discurso; (f) construção dos discursos do sujeito coletivo de cada quadro obtido na etapa anterior; (g) atribuição de um nome ou identificação para cada um dos discursos do sujeito coletivo ${ }^{8}$.

Desta forma, é de vital importância que as perguntas que compõem a entrevista sejam criteriosamente elaboradas, para que possamos obter respostas discursivas e não valorativas ${ }^{9}$.

\section{RESULTADOS}

\section{Caracterização dos sujeitos}

O grupo participante é formado por uma equipe multiprofissional constituída por quatro enfermeiras e três médicos, sendo um deles do sexo masculino, um terapeuta ocupacional e uma psicóloga.

\section{Idéias centrais e discursos do sujeito coletivo}

Os discursos do sujeito coletivo apresentados a seguir foram elaborados resumidamente por meio da idéia central. Foram utilizados pequenos artifícios - como a presença de conectivos entre parágrafos, para construir um discurso único do sujeito coletivo -, para efeito didático e uma resposta coletiva diante do questionamento. Ressalte-se, também, que os discursos obtidos no fórum utilizam literatura científica pertinente à temática, inerente à bagagem dos profissionais de Saúde que participaram do evento. Assim, nos resultados, os autores referendados através dos depoimentos dos participantes no fórum são utilizados como suporte teórico das discussões.

Os participantes foram identificados com a sigla $\mathrm{P}$, seguida do número de entrada no fórum: P1, P2 até P10, que é a constituição do grupo participante. Os grupos de discursos foram classificados de acordo com a idéia central e denominados grupos A, B, C e D.

\section{QUADRO 1}

Síntese das idéias centrais da pergunta: Como se deu historicamente a construção do conceito de cuidado a partir dos diferentes saberes-profissões?

\begin{tabular}{|l|l|}
\hline Grupo do discurso & Idéia central \\
\hline A & $\begin{array}{l}\text { Percepção do cuidado das diferentes } \\
\text { profissões }\end{array}$ \\
\hline B & $\begin{array}{l}\text { Integralidade na assistência como um dos } \\
\text { princípios do SUS }\end{array}$ \\
\hline
\end{tabular}


Idéia central: $O$ cuidado em suas diferentes formas segundo a percepção das diferentes profissões, considerando o conceito de ser humano e garantindo aos sujeitos que demandam o cuidado para a autonomia (P1, P2, P3, P4, P5).

Discurso do sujeito coletivo: Segundo a visão de mundo que os diferentes profissionais possuem, mesmo quando estão ainda na universidade, acaba por estabelecer um estilo de pensamento que adota como verdade absoluta. Diante de um conhecimento clínico, na maioria das vezes, pensa-se em tratar e não em cuidar. Historicamente, os indivíduos são formados numa rigidez das profissões que estabelece uma relação sujeito-objeto sem refletir sobre esse objeto e distanciando-se da relação sujeito-sujeito. $\mathrm{O}$ discurso médico está historicamente impregnado pelas relações hierárquicas estruturais e rituais de poder. A história da assistência nos mostra um novo despertar de uma nova consciência e de um sentimento humanitário, como também um espaço de apropriação e transformação de antigas estratégias de poderes.

Idéia central: Integralidade na assistência como um dos princípios do SUS no modelo de Saúde e a associação do saber técnico e político presente nas atividades dos cenários de ensino-aprendizagem (P1, P2, P3, P4, P5).

Discurso do sujeito coletivo: Considerando o modelo de atenção à saúde, vê-se que este estabelece intermediações entre o técnico e o político, que trazem em si a marca do risco e da tensão, posto que não é só político nem tampouco só tecnológico. Entre as esferas da técnica e do campo político há uma indissociabilidade dos campos clínicos e políticos que nos faz pensar que as políticas, os dados não são meras abstrações numéricas e, sim, cada um fala e traz uma história de vida cheia de complexidade. A integralidade da atenção e dos limites do cuidado solicita uma escuta qualificada e sensível das questões apontadas pela comunidade. No processo interativo nos cenários de ensino-aprendizagem, que fatores facilitadores são necessários para qualificar o olhar para ressignificá-los numa proposta de ativação de processo de mudança na formação de profissionais de Saúde? Acreditamos que os sujeitos não podem ser apenas sensíveis, a mudança precisa ser consistente, para diminuir as resistências, saber argumentar, sustentar posições, saber ouvir e ter uma boa dose de desprendimento e não pessoalizar as resistências e as críticas quando ocorrem.

Idéia central: Desejo dos profissionais de Saúde de inserção no processo de mudança (P1, P2, P3, P4, P5).

Discurso do sujeito coletivo: Quando iniciamos o processo reflexivo sobre a necessidade de mudança, constatamos que algo nos incomoda, que nos causa desconforto. Não um desconforto que produz paralisia, mas aquele que faz emergir a reflexão, a inquietude, a dúvida acerca das verdades insti-
QUADRO 2

Síntese das idéias centrais da pergunta:

Como lidar com uma experiência focal (inovadora) de ensino-aprendizagem?

\begin{tabular}{|c|l|}
\hline $\begin{array}{c}\text { Grupo do } \\
\text { discurso }\end{array}$ & \multicolumn{1}{c|}{ Idéia central } \\
\hline A & $\begin{array}{l}\text { O pensar e o refletir a educação na atualidade, } \\
\text { abrindo possibilidades de despertar nos } \\
\text { profissionais de Saúde o desejo do processo de } \\
\text { mudança. }\end{array}$ \\
\hline B & $\begin{array}{l}\text { Construção de rede de relações, de parceiros como } \\
\text { estratégias para o ensino inovador. }\end{array}$ \\
\hline C & $\begin{array}{l}\text { O espaço coletivo valida e acolhe as lideranças, } \\
\text { e é uma ferramenta importante no processo de } \\
\text { mudança. }\end{array}$ \\
\hline D & $\begin{array}{l}\text { Interação das instituições, docentes, discentes e } \\
\text { comunidade na escuta qualificada de uns aos outros. }\end{array}$ \\
\hline
\end{tabular}

tuídas previamente e desde sempre estabelecidas. Acreditamos ser nossa tarefa agir onde tudo permanece como verdade irrefutável, que o desconforto move e nos move no processo ensino-aprendizagem para a construção de novas e diferentes inquietações.

Idéia central: Construção de uma rede de parceiros na experiência focal do ensino inovador.

Discurso do sujeito coletivo: É preciso que tenhamos mais que um espaço de prática, mas essencialmente uma rede de relações, de parceiros, pois o que buscamos é construir um modelo de sociedade amplo e solidário. Quando a realidade histórica da instituição de ensino não permite no momento o salto qualitativo para a construção de um processo educacional que articule a formação com as necessidades e as demandas da sociedad, como estratégia eficaz para o desenvolvimento econômico e social desta nossa sociedade, é necessário que o docente consiga fazer alianças com outros docentes e profissionais do serviço. As parcerias possibilitam o crescimento, a visualização do melhor caminho para todas as instituições/ pessoas envolvidas no processo de mudança.

Idéia central: A liderança, ferramenta importante no processo de mudança, só pode ser percebida no processo coletivo.

Discurso do sujeito coletivo: A liderança precisa estimular as diferenças, explorar limites, promover a auto-organização de forma que educação, currículos e sistemas de Saúde possam trabalhar de modo complexo, atendendo a esse novo paradigma. A identificação do líder que constrói e ativa processos está diretamente ligada aos processos de autorização de um saber. O espaço coletivo valida e acolhe as lideranças. Essas lideranças são capazes de, no espaço coletivo, operar 
mudanças que promovam impacto no movimento de transformação.

Idéia central: A participação da instituição, docentes, discentes e comunidade desejando o processo de mudança.

Discurso do sujeito coletivo: A prática de mudança é difícil, porém necessária, em especial no interior das instituições e também no cotidiano, com docentes e estudantes, além da comunidade, que, por vezes, fica alheia às discussões tão necessárias à transformação do processo de ensinar-aprender e também de assistir-cuidar. Possibilitar ao estudante o exercício eficiente de seu trabalho, a participação consciente e crítica no mundo do trabalho e na esfera social, além de sua efetiva autorealização, passa pelo compromisso individual do docente-facilitador-tutor, pela vontade e curiosidade do estudante e sua continuidade com o apoio da instituição, da comunidade e com o estabelecimento de parcerias.

\section{QUADRO 3}

Síntese das idéias centrais da pergunta:

Como garantir a governabilidade-viabilidade às experiências no contexto da gestão?

\begin{tabular}{|l|l|}
\hline Grupo do discurso & Idéias centrais \\
\hline A & Programas de Saúde já existentes no SUS. \\
\hline B & $\begin{array}{l}\text { Caminhos e ferramentas da experiência } \\
\text { inovadora. }\end{array}$ \\
\hline C & $\begin{array}{l}\text { A pergunta qualificando o olhar e sua } \\
\text { relação com as práticas educativas e } \\
\text { conseqüentemente com as práticas do } \\
\text { cuidado. }\end{array}$ \\
\hline D & $\begin{array}{l}\text { Proposta do ensino inovador e a } \\
\text { construção da cidadania. }\end{array}$ \\
\hline
\end{tabular}

Idéia central: Refletindo sobre os programas de Saúde do SUS.

Discurso do sujeito coletivo: Alguns programas de Saúde foram construídos com base numa interação sujeito-sujeito, mas, na prática, permanece a relação sujeito-objeto. A relação sujeito-sujeito se dá quando o trabalho em Saúde revela uma ação que, desde o momento em que é concebida até o seu término, é feita no coletivo, seja sujeito-ator, serviço-clientela ou ainda profissional-cliente. Existem programas que são conduzidos por "euquipes", muitas vezes sem consistência. Isso porque certamente não ocorreria num contexto de cuidado integral em saúde, onde o papel do sujeito é construído em processo. O processo de mudança que queremos é aquele que é ativado num contexto integral, de construção sujeito-sujeito, de um sistema de Saúde e de educação, com base na sociedade, de forma intersetorial e interdisciplinar.
Idéia central: Caminhos e ferramentas da experiência inovadora.

Discurso do sujeito coletivo: As experiências inovadoras podem ter três caminhos: transformar o modelo de formação, constituir estruturas marginais no contexto tradicional e diluir-se no processo tradicional, perdendo seu poder inovador ao longo do tempo. Uma das ferramentas são os princípios e diretrizes do SUS e as propostas para a reforma curricular das profissões da área da Saúde. Outra ferramenta é a interação do professor com o diretor da instituição, viabilizada por meio das estratégias de gestão. Um caminho vislumbrado é o de iniciar na sua área de atuação, iniciar em sua própria aula, sendo protagonista de sua própria inovação. E ainda educar para além das fronteiras da universidade, indo para os serviços e comunidade, atuando diretamente em sua realidade. Entendemos que as interconexões que fazemos quando inovamos podem, de certa forma, constituir mecanismos de sustentabilidade, de adesão e de co-relações com a governabilidade interna e externa às instituições.

Idéia central: A pergunta qualifica o olhar e estabelece relação com as práticas educativas inovadoras e com as práticas do cuidado.

Discurso do sujeito coletivo: $\mathrm{O}$ debate sobre a prática do cuidado e sobre que cuidado a sociedade atual e a política de Saúde exigem passa por uma desconstrução teórica, com vistas a construir para a reconstrução em curso nas práticas de Saúde. Se os alunos souberem fazer as perguntas, já é uma etapa importante na busca das respostas. Na verdade, fomos catequizados, ao longo de nossa formação profissional, a não exercer o hábito e a forma de questionar, de perguntar. Repetimos isto em nossa vida e em nosso trabalho. Como reaprender a perguntar? Como construir, no processo ensino-aprendizagem, questões coerentes e consistentes? Passamos a refletir sobre como inquietar e levar os estudantes, os serviços de Saúde e a comunidade a refletirem e, portanto, a construírem perguntas, a respeito do cotidiano e da construção dos saberes. Como o facilitador pode atuar inquietando as pessoas, o mundo e a comunidade?

Idéia central: Proposta do ensino inovador e a construção da cidadania (P2, P4).

Discurso do sujeito coletivo: Na construção de um projeto político pedagógico inovador no que tange à extensão, a questão da interação ensino- trabalho se faz de forma a atender as necessidades da comunidade e dar continuidade a um projeto de ensino superior que atue na construção da cidadania. Nesse sentido, é de fundamental importância a avaliação da sociedade sobre o papel da universidade, bem como a análise do impacto da ação extensionista na transformação da própria 
universidade. A extensão é uma forma de ativar a mudança, traz elementos externos, circula na sociedade, rediscute o papel do ensino superior, deixa os "muros" da universidade, interage com atores e cenários diversificados e os co-relaciona.

\section{DISCUSSÃO}

De toda a produção teórica do grupo no fórum, entendese que os diferentes saberes e profissões determinam formas particulares do cuidado na área da Saúde, que são formadas e construídas a partir dos referenciais teóricos e das práticas específicas de cada campo do saber.

Historicamente, os indivíduos são formados numa rigidez das profissões que estabelece uma relação sujeito-objeto sem refletir sobre esse objeto e distanciando-se da relação sujeito-sujeito. Nesta relação está imbuída a compreensão do ser humano.

A retomada da relação sujeito-sujeito na formação superior dos profissionais de Saúde deve ser considerada um aspecto essencial na mudança que desejamos e precisamos.

O ser humano é transformado em sujeito a partir de sua inscrição em processos objetivantes. Neste caso, trata-se de subjetividades objetivadas por práticas discursivas e não discursivas, pelo engendramento deste ser humano em relações de saber-poder ${ }^{12}$.

Quanto mais um indivíduo interage com o outro, mais está apto a reconhecer comportamentos, intenções, valores, competências e conhecimento, para enfim ter uma percepção do outro ${ }^{13}$.

A respeito da formação dos profissionais de Saúde, observamos a perspectiva de uma capacitação maior, favorecendo a promoção e ações integrais de Saúde que beneficiem indivíduos e comunidades ${ }^{14}$. O perfil do profissional desejado e esperado para atender a população revela a necessidade de implementar estratégias de mudança dos atuais modelos acadêmicos. Para isso, é fundamental compreender adequadamente os limites e as possibilidades das inovações e das reformas da educação médica frente ao perfil das práticas médicas hegemônicas e frente às estruturas sociais no contexto dos processos de globalização ${ }^{14}$.

As transformações da prática passam pela emergência e valorização de novos saberes, por uma postura mais dialógica da equipe entre si e com os usuários, por uma abertura conceitual e científica em relação ao modelo da biomedicina e maior responsabilidade política e ideológica dos gestores ${ }^{15}$.

Essas transformações são essenciais na construção de vínculo e aproximam quem oferece ou presta o serviço de quem o recebe, e personalizam a relação, que deve ser compromissada, solidária e surgir como fruto de uma construção social e parte de um esforço que envolve equipe, instituições e comunidade ${ }^{3}$.
A noção do vínculo nos faz refletir sobre responsabilidade e compromisso. Essa noção de vínculo está em consonância com o sentido de integralidade. Para Mehry ${ }^{16}$, criar vínculo implica ter relações tão próximas e tão claras, que nos sensibilizamos com todo o sofrimento daquele outro, sentindo-nos responsáveis pela vida e morte do paciente, o que possibilita uma intervenção que não seja burocrática nem impessoal.

No que tange a um dos princípios do SUS, a integralidade existe em ato e pode ser demandada na organização de serviços e renovação das práticas de Saúde, sendo reconhecida nas práticas que valorizam o cuidado e que têm em suas concepções a idéia-força de considerar o usuário como sujeito a ser atendido e respeitado em suas demandas e necessidades². O processo de mudança no ensino exige muito mais que um espaço de prática, deve ser construído em parcerias para que seja possível produzir conhecimento e inovação ${ }^{17}$.

A inovação é toda tentativa que visa, consciente e deliberadamente, introduzir uma mudança no sistema de ensino com a finalidade de melhorá- $1 \mathrm{o}^{18}$.

A sobrevivência da universidade depende de sua reinserção na sociedade, da construção de novas relações e de um novo papel socialmente mais relevante, e a mudança da formação do profissional de Saúde deve ser ancorada nessas necessidades ${ }^{14}$.

Acreditando na formação de um profissional crítico para atender as necessidades reais da população, o melhor caminho é questionar e praticar a crítica na prática. Nessa prática estão imbuídas as mudanças que almejamos na formação superior dos profissionais de Saúde - educação tradicional para educação inovadora -, para haver mudanças nas práticas de Saúde.

\section{CONSIDERAÇÕES FINAIS}

A mudança se inicia com o rompimento do paradigma tradicional do processo de ensino-aprendizagem e identificação dos limites e possibilidades das inovações desejadas.

Quando o sujeito social se propõe a ser facilitador de um processo de mudança na educação, dá o primeiro passo para a reconstrução da prática educativa, aprendendo com os demais atores - alunos, usuários, professores, profissionais - novas atitudes, reconstruindo velhas formas de pensar e fazer saúde e propiciando uma atualização para a frente, produzindo, ao final, uma mudança das práticas pedagógicas, dos fazeres e dos homens.

Uma estratégia viável é transpor as fronteiras da sala de aula por meio de um modelo pedagógico que equilibre a excelência técnica e a relevância social, com métodos ativos de ensino-aprendizagem centrados nos alunos; inserir a vivência prática, destinando parte da carga horária a reflexões e ati- 
vidades com e nos próprios serviços de Saúde, com base na relação de parceria da universidade com os serviços de Saúde, com a comunidade, com as entidades e outros setores da sociedade civil.

Desta perspectiva, ainda que as iniciativas sejam isoladas, devem ser incentivadas e acreditadas como um primeiro passo para a mudança. Um cotidiano mais produtivo e confortável no ambiente de trabalho pode ser resultante de uma experiência isolada com agregação de parceiros ao longo do caminho, embusca de uma construção coletiva de experiências inovadoras.

\section{REFERÊNCIAS}

1. Vasconcellos CS. Avaliação: concepção dialética-libertadora do processo de avaliação escolar. 16 ed. São Paulo: Libertad; 2006.

2. Pinheiro R, Mattos RA. Os sentidos da integralidade na atenção e no cuidado à saúde. Rio de Janeiro: IMS/UERJ; 2001.

3. Silva RVB, Stelet BP, Pinheiro R, Guizardi FL. Do elo ao laço: $\mathrm{O}$ agente comunitário na construção da integralidade em saúde. In: Pinheiro R, Mattos RA. (Org.) Cuidado: as fronteiras da Integralidade. Rio de Janeiro: IMS/UERJ; Hucitec; 2004. p. 5-90.

4. Zanotto MAC, De Rose TMS. Problematizar a própria realidade: análise de uma experiência de formação contínua. Educação e Pesquisa 2003;29(1):45-54.

5. Levy P. L'Intelligence Collective. Pour une Antropologie du Cyberspace. Paris: La Descouverte;1994.

6. Campos FE, Ferreira JR, Feuerwerker L, Sena RR, Campos JJB, Cordeiro $\mathrm{H}$ et al. Caminhos para aproximar a formação de profissionais de saúde das necessidades da atenção básica. Rev Bras Educ Med. 2001;25(2): 53-59.

7. Ferrero YP. Grupos operativos y educación para la salud: Experiencia en el hospital "A. Zatti", Viedma Argentina. [online]. [Acesso em 28 nov. 2005]. Disponível em: http:/ / www.monografias.com/trabajos11/cerodos/cerodos. shtml

8. Simioni AMC. O gerenciamento de recursos humanos em saúde como processo social. São Paulo; 1996. Dissertação [Mestrado] - Universidade de São Paulo, Faculdade de Saúde Pública.

9. Lefréve F, Lefréve AMC, Teixeira JJV. O discurso do sujeito coletivo: uma nova abordagem metodológica na pesquisa qualitativa. Caxias do Sul: EDUCS; 2002.

10. Simioni AMC, Lefréve F, Pereira Bicudo IMT. Metodologia qualitativa nas pesquisas em saúde coletiva: considerações teóricas e instrumentais. São Paulo Edusp; 1997.
11. Lefréve AMC, Lefréve F, Cardoso MRL, Mazza MMPR. Assistência à saúde Pública no Brasil: estudo de seis ancoragens. Saúde soc 2005;11(2):35-47.

12. Peres MFT, Almeida Filho NM. A nova psiquiatria transcultural e a reformulação na relação entre as palavras e as coisas. Interface comun. saúde educ. 2005; 9(17): 275-85.

13. Costa R. Por um novo conceito de comunidade: redes sociais, comunidades pessoais, inteligência coletiva. Interface comun. saúde educ. 2000; 59(17): 235-48.

14. Almeida MJ. Educação Médica e Saúde: possibilidades de mudança. Londrina: Ed.; Rio de Janeiro: ABEM;1999.

15. Favoreto CAO, Camargo JR. Alguns desafios conceituais e técnico-operacionais para o desenvolvimento do programa de saúde da família como uma proposta transformadora do modelo assistencial. Physis 2002; 12(1): 59-76.

16. Merhy EE. Em busca da qualidade dos serviços de saúde: os serviços de porta aberta para a saúde e o modelo tecnoassistencial em defesa da vida (ou como aproveitar os ruídos do cotidiano dos serviços de saúde e colegiadamente reorganizar o processo de trabalho na busca da qualidade das ações de saúde). In: Cecílio LCO. Inventando a mudança em saúde. São Paulo: Hucitec; 1994. p.116-160.

17. Leite DB. Inovação na Universidade: a pesquisa em parceria. Interface comun. saúde educ 1999; 3(4): 41-52.

18. Castanho ME. Professores de ensino superior da área da saúde e sua prática pedagógica. Interface comun. saúde educ. 2006;6(10):51-62.

\section{CONTRIBUIÇÃO DOS AUTORES}

Maria de Lourdes da S. Marques Ferreira foi a responsável pela coordenação, planejamento, e trabalhou na redação do manuscrito. Rosângela Minardi Mitre Cotta participou do planejamento e auxiliou na redação e revisão do manuscrito. Marilda Siriani de Oliveira participou do planejamento, orientação, e acompanhamento do trabalho e auxiliou a revisão do manuscrito.

\section{CONFLITO DE INTERESSES}

Declarou não haver

\section{ENDEREÇO PARA CORRESPONDÊNCIA}

Maria de Lourdes da Silva Marques Ferreira

Distrito de Rubião Júnior, $\mathrm{s} / \mathrm{n}^{\circ}$ Campus Universitário

Botucatu - São Paulo

CEP.: 18609780 SP

E-mail: malusa@fmb.unesp.br 